\title{
Localizing the nerve to the mylohyoid using the mylohyoid triangle
}

\author{
Joe Iwanaga ${ }^{1,2,3,4}$, Hee-Jin Kim ${ }^{5}$, Grzegorz Wysiadecki ${ }^{6}$, Kyoichi Obata ${ }^{8}$, Yosuke Harazono ${ }^{7}$ \\ Soichiro Ibaragi ${ }^{8}$, R. Shane Tubbs ${ }^{1,2,9,10,11}$
}

${ }^{1}$ Department of Neurosurgery, Tulane Center for Clinical Neurosciences, Tulane University School of Medicine, New Orleans, LA, ${ }^{2}$ Department of Neurology, Tulane Center for Clinical Neurosciences, Tulane University School of Medicine, New Orleans, LA, USA, ${ }^{3}$ Dental and Oral Medical Center, Kurume University School of Medicine, Kurume, ${ }^{4}$ Division of Gross and Clinical Anatomy, Department of Anatomy, Kurume University School of Medicine, Kurume, Japan, ${ }^{5}$ Division in Anatomy and Developmental Biology, Department of Oral Biology, Human Identification Research Institute, BK21 FOUR Project, Yonsei University College of Dentistry, Seoul, Korea, ${ }^{6}$ Department of Normal and Clinical Anatomy, Chair of Anatomy and Histology, Medical University of Lodz, Lodz, Poland, ${ }^{7}$ Department of Maxillofacial Surgery, Graduate School of Medical and Dental Science, Tokyo Medical and Dental University, Tokyo, ${ }^{8}$ Department of Oral and Maxillofacial Surgery, Okayama University Graduate School of Medicine, Dentistry and Pharmaceutical Sciences, Okayama, Japan, ${ }^{9}$ Department of Anatomical Sciences, St. George's University, St. George's, Grenada, ${ }^{10}$ Department of Structural \& Cellular Biology, Tulane University School of Medicine, New Orleans, LA, ${ }^{11}$ Department of Neurosurgery and Ochsner Neuroscience Institute, Ochsner Health System, New Orleans, LA, USA

\begin{abstract}
The nerve to the mylohyoid muscle has been well studied but there are no specific anatomical landmarks for identifying it. Therefore, we aimed to identify anatomical landmarks for localizing the nerve to the mylohyoid muscle in the submandibular region. Sixteen sides from eight embalmed Caucasian cadaveric heads were used in this study. The mean age at the time of death of the specimens was 80.3 years. The anterior and posterior bellies of the digastric muscle, submental artery, and mylohyoid muscle were dissected to verify their relationships with the nerve to the mylohyoid muscle. The nerve to the mylohyoid muscle was found medial to the submental artery, lateral to the anterior belly of the digastric muscle, and anterior to the posterior border of the mylohyoid muscle on all sides. Herein, we identified what we term the mylohyoid triangle. This anatomical region can help localize the nerve to the mylohyoid muscle.
\end{abstract}

Key words: Nerve to mylohyoid muscle, Submental island flap, Reconstructive surgery, Head and neck surgery, Submental artery

Received February 5, 2021; Revised March 18, 2021; Accepted April 5, 2021

\section{Introduction}

The nerve to the mylohyoid muscle has been well studied in various anatomical studies $[1,2]$. Nevertheless, it is not well noted in the surgical record due to its perceived less clinical importance. The nerve to the mylohyoid muscle is known to run in the submandibular triangle and innervate

\footnotetext{
Corresponding author:

Joe Iwanaga (iD

Department of Neurosurgery, Tulane Center for Clinical Neurosciences, Tulane University School of Medicine, New Orleans, LA 70112, USA E-mail: iwanagajoeca@gmail.com
}

the mylohyoid and anterior belly of the digastric muscles [3, 4]. It might also innervate the skin of the chin [1]. However, for improved access to the nerve, detailed anatomical landmarks are necessary. Additionally, the depth and relationships with adjacent anatomical structures is required for the most precise localization of the nerve.

Recently, head and neck reconstructive surgeries such as genioplasty, submandibulectomy, sagittal split ramus osteotomy, and the creation of a submental island flap (SMIF) requires an accurate knowledge of the submandibular region for avoiding iatrogenic complications [5-10]. Localizing the nerve to the mylohyoid might be of help for surgeons.

Therefore, in this study, we aimed to identify better anatomical landmarks for locating the nerve to the mylohyoid 

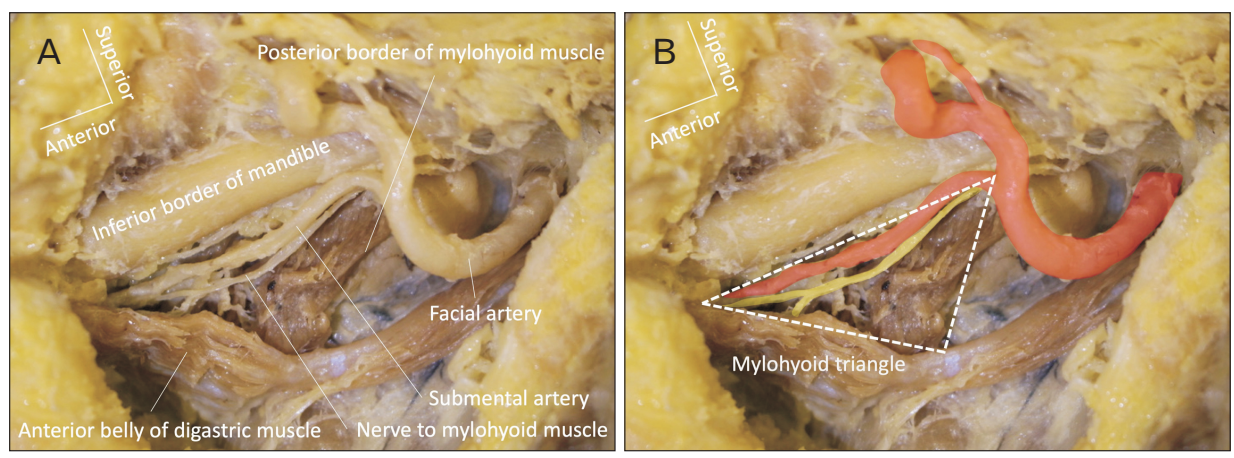

Fig. 1. The mylohyoid triangle (B) and the adjacent anatomical structures that form its borders (A). muscle in the submandibular region.

\section{Materials and Methods}

Sixteen sides from eight embalmed cadaveric heads were used in this study. The cadavers were derived from five females and three males. The mean age at the time of death was 80.3 years (range, $72-87$ years). A skin incision was made in the submandibular area approximately two fingers breadths below the inferior border of the mandible. The platysma was then incised to reach the deep cervical fascia. The anterior and posterior bellies of the digastric muscle, facial artery, submental branch of the facial artery, and mylohyoid muscle were dissected to verify their relationships to the nerve to the mylohyoid muscle. The submandibular gland was removed when it covered the nerve to the mylohyoid muscle. All dissections were performed by the first author (JI) using a surgical microscope (Zeiss, Oberkochen, Germany). No previous surgical scars were observed in the dissected area. The present study was performed in accordance with the requirements of the Declaration of Helsinki (64th WMA General Assembly, Fortaleza, Brazil; October 2013).

\section{Results}

The anterior and posterior bellies of the digastric muscle and mylohyoid muscle were found on all sides $(100 \% ; 16 / 16)$. The submental artery was found on all sides $(100 \% ; 16 / 16)$. Bifurcation of the submental artery from the facial artery was observed on or posterior to the posterior border of the mylohyoid muscle. The nerve to the mylohyoid muscle was found medial to the submental artery, lateral to the anterior belly of the digastric muscle, and anterior to the posterior border of the mylohyoid muscle on all sides (100\%; 16/16). The course and depth of the submental artery varied on each side, the nerve always run nearby the mylohyoid muscle. We termed this anatomical region the mylohyoid triangle (Fig. 1). The mylohyoid triangle is located anterior to the triangle of Pirogoff [11], and overlaps with the anterior part of the Lesser's triangle [4], although the depth is different. No anatomical variations of the digastric muscle or mylohyoid muscle was noted.

\section{Discussion}

As mentioned earlier, the nerve to the mylohyoid muscle innervates not only the mylohyoid and anterior belly of the digastric muscles but also can innervate the lingual cortical plate of the mandible and the skin of the chin area. Thus, some reported that injury to the nerve to the mylohyoid might be a potential cause of complications following surgical procedures along its course [12]. Altug et al. [13] noted nerve to the mylohyoid muscle blockade as an alternative method for inferior alveolar nerve blockade because the nerve to the mylohyoid muscle is considered to supply supplementary innervation to the lower molar tooth. Potu et al. [14] described that a variation of the nerve to the mylohyoid communication with the lingual nerve was found. In support of this anatomical finidng, permanent or transient sensory loss around the skin of the chin except the lower lip has been reported as a postoperative complication of genioplasty, submandibulectomy, and sagittal spilt ramus osteotomy [58]. Therefore, avoiding injury to the nerve to the mylohyoid muscle might decrease such postoperative complications.

Some have advocated use of the nerve to the mylohyoid muscle for facial nerve reanimation procedures. Tubbs et al. [15] performed a cadaveric study that analyzed the nerve to mylohyoid muscle as a donor nerve for neurotization of an ipsilateral injured facial nerve. The authors found that the mean length available of the donor nerve was $5.5 \mathrm{~cm}$ and 
that the nerve could easily reach the facial nerve stem and its temporofacial and cervicofacial trunks without tension. Use of the mylohyoid triangle could, therefore, assist the surgeon who might perform such a procedure by better localizing the nerve to the mylohyoid muscle.

Various anatomical studies on the nerve to the mylohyoid muscle have been reported. Descending and showing up in the submandibular area, the nerve runs between the mylohyoid and anterior belly of the digastric muscles and innervates these muscles [2]. Cutaneous branches to the submental skin have also been observed [1]. Additionally, the lingual nerve often communicates with the nerve to the mylohyoid muscle [2]. Aberrant branching of the nerve and dual innervation of the mylohyoid muscle by the nerve to the mylohyoid muscle and hypoglossal nerve have been reported [16-18].

In the present study, the submental artery, anterior belly of the digastric muscle, and posterior border of the mylohyoid muscle were used to locate the nerve. The nerve to the mylohyoid muscle was identified within the three structures on all sides (100\%). We propose that such a geometric region be termed the mylohyoid triangle. The advantage of using such a triangle as compared to using the submandibular triangle is that three dimensional relationships with adjacent structures are better appreciated. The nerve to the mylohyoid muscle can be found within the submandibular triangle, but the depth of the nerve is not clear. The mylohyoid triangle has a depth to accommodate the nerve to the mylohyoid muscle so that surgeons or anatomists can easily access the nerve. We need to keep in our mind that the course of the nerve can be affected by the size and location of the submandibular gland. Also, as it is well known, anterior belly of the digastric muscle is one of the suprahyoid muscles that often shows anatomical variation [19].

Recent reports in the head and neck reconstructive surgery literature have reported the benefits of using a SMIF $[9,10]$. Depending on the lesion volume that is resected, the SMIF includes the anterior belly of the digastric muscle with or without the mylohyoid muscle. When only the anterior belly of the digastric muscle is sacrificed, the mylohyoid branch of the nerve to the mylohyoid muscle could be preserved. Therefore, the mylohyoid triangle might help surgeons find the nerve to the mylohyoid muscle during separation from the island flap tissue when the mylohyoid muscle is preserved and so that functional preservation of the muscle occurs.

In conclusion, we found that the nerve to mylohyoid muscle is always identified within what we have coined, the mylohyoid triangle in the present study. Although anatomical variations can affect the triangle, such a finding might help surgeons more quickly identify this nerve and avoid any complications associated with its injury.

\section{ORCID}

Joe Iwanaga: https://orcid.org/0000-0002-8502-7952

Hee-Jin Kim: https://orcid.org/0000-0002-1139-6261

Grzegorz Wysiadecki:

https://orcid.org/0000-0003-3631-2295

Kyoichi Obata: https://orcid.org/0000-0002-6569-7406

Yosuke Harazono: https://orcid.org/0000-0002-3989-0210

Soichiro Ibaragi: https://orcid.org/0000-0003-2897-1231

R. Shane Tubbs: https://orcid.org/0000-0003-1317-1047

\section{Author Contributions}

Conceptualization: RST, JI. Data acquisition: RST, JI. Data analysis or interpretation: JI, HJK, GW. Drafting of the manuscript: JI, KO, YH. Critical revision of the manuscript: SI, RST. Approval of the final version of the manuscript: all authors.

\section{Conflicts of Interest}

No potential conflict of interest relevant to this article was reported.

\section{Acknowledgements}

The authors sincerely thank those who donated their bodies to science so that anatomical research could be performed. Results from such research can potentially increase mankind's overall knowledge that can then improve patient care. Therefore, these donors and their families deserve our highest gratitude [20].

\section{References}

1. Ryu EJ, Kim DH. Anatomical insights of the mylohyoid for clinical procedures in dentistry. Clin Anat 2021;34:461-9.

2. Koga S, Sato I, Li ZL, Miyaso H, Kawata S, Itoh M. Analysis of the mylohyoid nerve in elderly Japanese cadavers for dental implant surgery. Clin Exp Dent Res 2021;7:20-32.

3. Standring S. Gray's anatomy: the anatomical basis of clinical 
practice. 42nd ed. Amsterdam: Elsevier; 2020.

4. Kikuta S, Iwanaga J, Kusukawa J, Tubbs RS. Triangles of the neck: a review with clinical/surgical applications. Anat Cell Biol 2019;52:120-7.

5. Adjei SS, Hammersley N. Mylohyoid nerve damage due to excision of the submandibular salivary gland. Br J Oral Maxillofac Surg 1989;27:209-11.

6. Guyot L, Layoun W, Richard O, Cheynet F, Gola R. Alteration of chin sensibility due to damage of the cutaneous branch of the mylohyoid nerve during genioplasty. J Oral Maxillofac Surg 2002;60:1371-3.

7. Oth O, Louryan S, Van Sint Jan S, Rooze M, Glineur R. Impact of the mandibular divergence on the position of the inferior alveolar nerve and mylohyoid nerve: a computed tomography study and its relevance to bilateral sagittal split osteotomy. Surg Radiol Anat 2013;35:241-7.

8. Choi P, Iwanaga J, Dupont G, Oskouian RJ, Tubbs RS. Clinical anatomy of the nerve to the mylohyoid. Anat Cell Biol 2019;52:12-6.

9. Hu S, Fan C, Pecchia B, Rosenberg JD. Submental island flap vs free tissue transfer in oral cavity reconstruction: systematic review and meta-analysis. Head Neck 2020;42:2155-64.

10. Bayon R, Davis AB. Submental flap for soft tissue reconstruction following radical parotidectomy. Otolaryngol Head Neck Surg 2019;160:1130-2.

11. Pirogov NI. Anatome topographica: sectionibus per corpus humanum congelatum: triplici directione ductis illustrata. Petropoli: Typis Jacobi Trey; 1852.

12. Varol A, Sencimen M, Kocabiyik N, Gulses A, Ozan H. Clinical and anatomical aspects of possible mylohyoid nerve injury during genioplasties. Int J Oral Maxillofac Surg 2009;38:10847.
13. Altug HA, Sencimen M, Varol A, Kocabiyik N, Dogan N, Gulses A. The efficacy of mylohyoid nerve anesthesia in dental implant placement at the edentulous posterior mandibular ridge. J Oral Implantol 2012;38:141-7.

14. Potu BK, D'Silva SS, Thejodhar P, Jattanna NC. An unusual communication between the mylohyoid and lingual nerves in man: its significance in lingual nerve injury. Indian J Dent Res 2010;21:141-2.

15. Tubbs RS, Loukas M, Shoja MM, Acakpo-Satchivi L, Wellons JC 3rd, Blount JP, Oakes WJ. The nerve to the mylohyoid as a donor for facial nerve reanimation procedures: a cadaveric feasibility study. J Neurosurg 2007;106:677-9.

16. Iwanaga J, Kikuta S, Oskouian RJ, Tubbs RS. Nerve to mylohyoid branched from the lingual nerve: previously undescribed case. Anat Sci Int 2019;94:266-8.

17. Shen D, Do Q, Ohyama H, Tubbs RS, Iwanaga J. Dual innervation of the mylohyoid muscle by the trigeminal and hypoglossal nerves: a case report. Morphologie 2021;105:72-4.

18. Ryumon S, Hage D, Ibaragi S, Okui T, Tubbs RS, Iwanaga J. Dual innervation of the submandibular gland by nerve to mylohyoid and chorda tympani. Morphologie 2020 Dec 4 [Epub]. https://doi.org/10.1016/j.morpho.2020.11.004.

19. Kim SD, Loukas M. Anatomy and variations of digastric muscle. Anat Cell Biol 2019;52:1-11.

20. Iwanaga J, Singh V, Ohtsuka A, Hwang Y, Kim HJ, Moryś J, Ravi KS, Ribatti D, Trainor PA, Sañudo JR, Apaydin N, Şengül G, Albertine KH, Walocha JA, Loukas M, Duparc F, Paulsen F, Del Sol M, Adds P, Hegazy A, Tubbs RS. Acknowledging the use of human cadaveric tissues in research papers: recommendations from anatomical journal editors. Clin Anat 2021;34:24. 